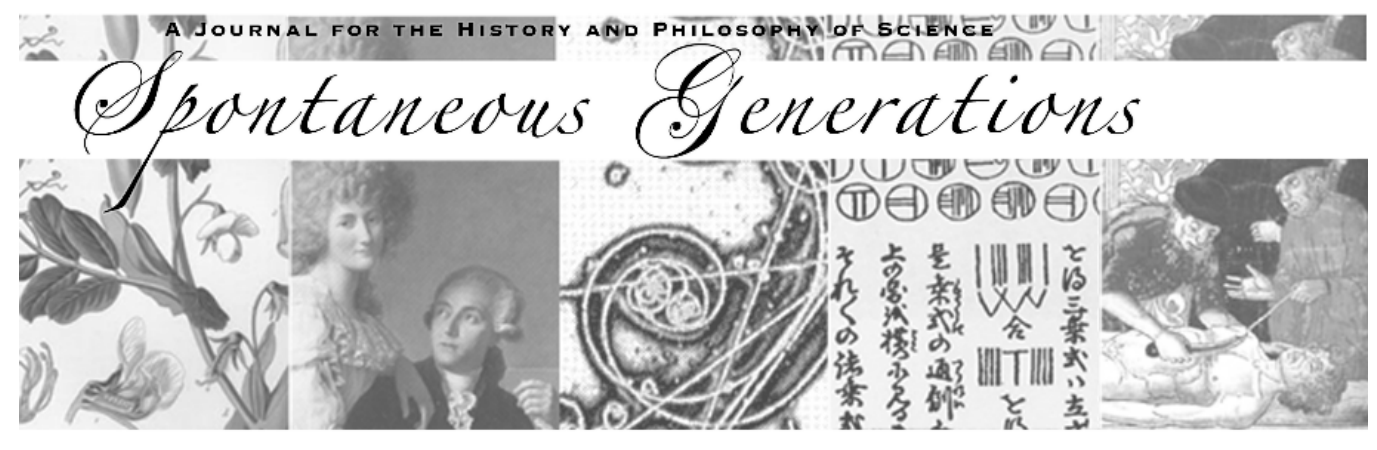

"That small and unsensible shape": Visual Representations of the Euclidean Point in Sixteenth-Century Print

Author(s): Michael J. Barany

Source: Spontaneous Generations: A Journal for the History and Philosophy of Science, Vol. 6, No. 1 (2012) 148-159.

Published by: The University of Toronto

DOI: $\underline{10.4245 / \text { sponge.v6i1.16137 }}$

\author{
EDITORIAL OFFICES \\ Institute for the History and Philosophy of Science and Technology \\ Room 316 Victoria College, 91 Charles Street West \\ Toronto, Ontario, Canada M5S 1K7 \\ hapsat.society@utoronto.ca
}

Published online at jps.library.utoronto.ca/index.php/SpontaneousGenerations

ISSN 19130465

Founded in 2006, Spontaneous Generations is an online academic journal published by graduate students at the Institute for the History and Philosophy of Science and Technology, University of Toronto. There is no subscription or membership fee. Spontaneous Generations provides immediate open access to its content on the principle that making research freely available to the public supports a greater global exchange of knowledge. 


\title{
"That small and unsensible shape" Visual Representations of the Euclidean Point in Sixteenth-Century Print ${ }^{*, \dagger}$
}

\begin{abstract}
Michael J. Barany
This paper probes the foundations and limits of visual representation in the sciences through a close reading of the diagrams that accompanied definitions of the geometric point in the first century of printed editions of Euclid's Elements. I begin with the modal form for such diagrams of Euclid's "small and unsensible shape," showing how it incorporates a broad spectrum of conventions and practices related to the point's philosophical and practical roles in the surrounding Euclidean geometry. I then explore the form's several variations in order to consider the role of "mere representation" in geometric exegesis, and conclude by characterizing the curious relationship between things and their images and that relationship's implications for understanding scientific knowledge and practice.
\end{abstract}

The point is, before all else, a beginning. It is the first entity to appear in Euclid's Elements, but that is just the start. Sixteenth-century polymath Robert Recorde (1551, Sig. $A 1^{r}$ ) described the point as the "first touch" of a pen or pencil. Recorde's contemporary Henry Billingsley (1570, Fol. $1^{r}$ ), the first to translate the whole of the Elements into English, called the point "the beginning of magnitude." According to the Big Bang theory, the Universe itself starts as a point. In analytic geometry, the axes of each space meet at a point called "the origin." In these examples, the point is a beginning at once conceptual, logical, narrative, material, and visual. This is thus an essay about how to begin.

Specifically, this is an essay about the visual representation of beginnings, the beginnings of visual representation, and the relationship between the two. Points of many kinds can be seen throughout images in and outside of science. Maps have coordinate points. Plots have data points. Digital images are arrays of pixels-colored points. Point perspective was a hallmark of

* This material is based upon work supported by a National Science Foundation Graduate Research Fellowship (Grant No. DGE-0646086). I would like to thank Margaret Schotte, Gregg De Young, Anthony Grafton, Pamela Long, Jimena Canales, Janet Vertesi, Evan Hepler-Smith, Yulia Frumer, Stephanie Kelly, the participants in the 2011 Princeton-Harvard-MIT History of the Physical Sciences Workshop and in Princeton's History of Science Program Seminar, and my anonymous referees for helpful discussions and suggestions.

† Received 24 February 2012. Accepted 3 August 2012.

¥ Michael is a PhD candidate in Princeton University’s Program in History of Science. 
Renaissance art, Pointillism an influential modern technique. Points are visually and conceptually fundamental in the mathematics of sets, the chemistry of atoms, and the physics of particles.

At the same time, the Euclidean point seems a strange (even absurd) case for a study of visual representation. "A point," begins the Elements, "is that which has no part" (Heath 1956, 155). The point is the one thing in Euclid's geometry with a purely negative definition. It has no constituent parts and cannot be subdivided. Recorde (1551, Sig. $A 1^{r}$ ) called the point "that small and unsensible shape.” Nothing to see here.

Put another way, the point appears in Euclidean geometry as if from nowhere. I would like to call attention to two features of this paradoxical apparition. First and foremost in this essay, the point nevertheless must be made to appear. Expositors of geometry manifest points through a constellation of visual, textual, narrative, corporeal, and technical means. ${ }^{1}$ But, second, this manifestation makes points appear so simple as hardly to need such representation. This disappearing act is a fundamental feature of the point's meaning and its place at the start of Euclidean geometry. Now you see it, now you don't.

This double work of representation is particularly perspicuous in the century of print publications of the Elements following Venice printer Erhard Ratdolt's landmark 1482 edition. That century witnessed significant changes in the social, technical, institutional, linguistic, and intellectual contexts of Euclidean geometry. In the surge of printed volumes that sixteenth-century editors and printers produced for a range of audiences, the point is almost always depicted with its own diagram alongside those for other Euclidean definitions. ${ }^{2}$ Below, I consider these visual depictions from a number of prominent editions and commentaries reflecting a variety of publishers, editors, and cities of origin. ${ }^{3}$

1 My approach is thus sympathetic to the cognitive project of Lakoff and Núñez, who stress the cognitive and conceptual heterogeneity of the fundamental concepts of mathematics, including points. Likewise, Rotman emphasizes the semiotic hybridity layered into taken-for-granted mathematical notations. Methodologically, my focus on the technical and semiotic features of particular historical phenomena of representation-work places this study closer to those of Lynch (1985) and Livingston. See G. Lakoff, and R. Núñez, Where Mathematics Comes From: How the Embodied Mind brings Mathematics into Being, (New York: Basic Books, 2000); B. Rotman, Towards a semiotics of mathematics, Semiotica 72-1/2 (1988): 1-35; B. Rotman, Ad Infinitum: The Ghost in Turing's Machine, Taking God Out of Mathematics and Putting the Body Back in, an Essay in Corporeal Semiotics, (Stanford: Stanford University Press, 1993); and E. Livingston, The Ethnomethodological Foundations of Mathematics, (London: Routledge, 1986).

2 Netz $(1998,38)$ claims that point illustrations were the norm in the older Euclidean manuscript tradition as well. I thank Gregg De Young for noting to me the limitations of Netz's claim for medieval Byzantine and Arabic manuscripts. Point illustrations are much less common in the seventeenth century, and extremely rare thereafter.

3 This selection of texts is indicative but not comprehensive. My analysis leaves aside the works' 
Rather than assert the historical distinctiveness of sixteenth-century point depictions, I offer a close reading of the representational labor manifested in this transitional period for the Elements in order to explore the foundations and limits of visual representation across the historical sciences. In one sense, the Euclidean point is an extreme case: if something assumed to be so trivial involves so much representational work, then other visual representations must be all the more work-laden. At the same time, I contend that, despite the Euclidean point's special status in and beyond the Elements, it is an object of knowledge like any other. What follows is thus both a case for the complexity and importance of visual representations and a proposal for how to read them.

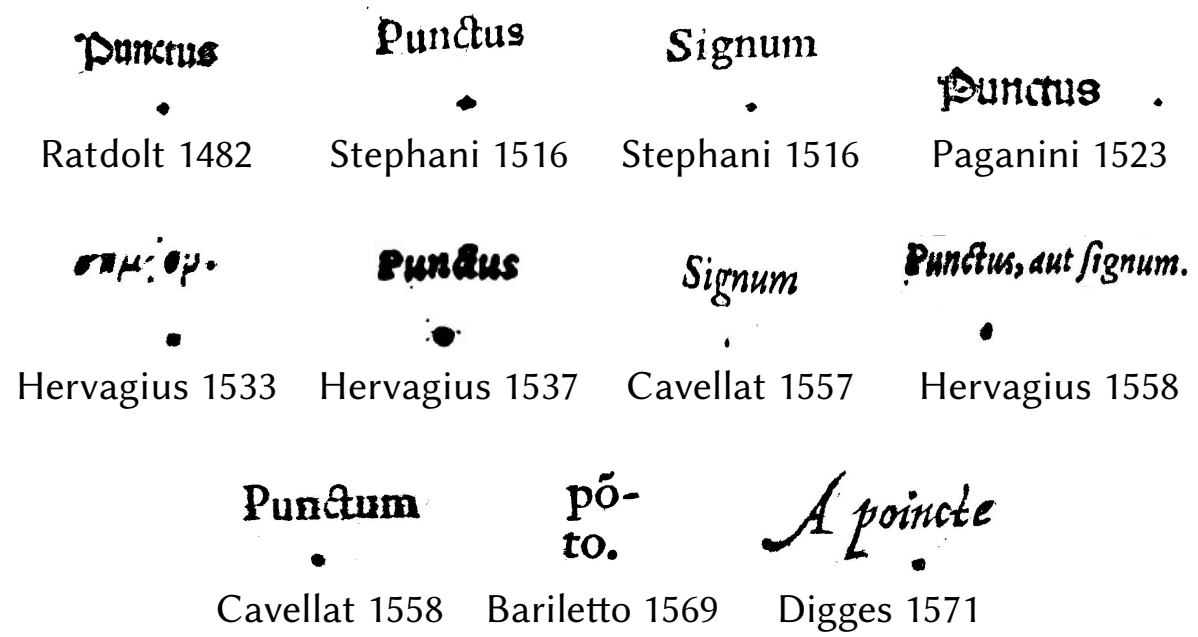

Figure 1. Authors as noted. "Label-dot" definitional diagrams. ${ }^{4}$

\section{LABELS AND DOTS}

The predominant sixteenth-century illustration of the Euclidean point is the "label-dot" diagram, which features a fully spelled-out label, often followed by a punctuational period, with a single dot centered below it (Figure 1). The diagram was placed near the formal sentence defining the point or near an explanatory passage following that sentence. In Ratdolt's 1482 edition (and in many others, but not all), the dot is the same size and shape as the punctuational periods that appear elsewhere on the page. The labels themselves are often rendered in a standard typeface, although sometimes they are smaller (as in Ratdolt's case)

publication histories, many of which have been treated by others.

4 Images appear by permission of the Master and Fellows of St. John's College, Cambridge (Digges), Princeton University Library (Stephani, Hervagius 1537 and 1558; Cavellat 1558; Bariletto), and Cornell University Library Division of Rare and Manuscript Collections (Ratdolt, Paganini, Hervagius 1533; Cavellat 1557). 
or larger than printed letters in the nearby text. In other cases, such as Digges (1571), the labels are incorporated into a woodcut along with the dot and other figures and appear in an entirely different script from the surrounding text.

Label-dot diagrams can be understood in a number of distinctive ways. First, it is possible to read such diagrams alone or in the context of other images without referring to the definitional sentence they accompany. The label placed above (and thus prior to) the dot offers an Adamic designation that efficiently announces the dot as a point in a context that can be scanned quickly or contemplated slowly. The pattern of naming and showing, of course, could be found beyond the page in realms as varied as natural history and language instruction. ${ }^{5}$

With space on expensive paper or parchment at a premium, the label-dot format made possible a wide range of efficient arrangements for text and images. Publishers inherited from the manuscript tradition a variety of conventions for such arrangements, most of which involved reserving a portion of the page for one or more figures. ${ }^{6}$ For instance, Ratdolt and Paganini largely placed their diagrams in margins, while Hervagius used both horizontal bands of space and reserved rectangles that interrupted the main body of text. Compositional challenges were particularly acute at the beginning of the Elements, which opens with a large number of short definitional sentences and a correspondingly large number of simple diagrams. While some cues and arrangements could be used to differentiate the definitional sentences, the most reliable way to present a maximum of surveyable information in a minimum of space and with a minimum of ambiguity was a tightly-packed region of economically labeled diagrams.

These clusters of images could be read in their own right for mathematical information. Most importantly, whether arranged in rough proximity to their definitions (as with Ratdolt) or organized into thematic series (as with Digges or

5 The dominance of pointing and naming is often taken for granted in the sociology of science literature, see e.g. B. Barnes, T.S. Kuhn and Social Science, (New York: Columbia University Press, 1982, chap. 2). For natural-historical name-image pairing, see, e.g., N. Jardine, J. A. Secord, and E.C. Spary, eds, Cultures of Natural History, (Cambridge: Cambridge University Press, 1996, esp. chap. 2); and S. Kusukawa, The uses of pictures in the formation of learned knowledge: The cases of Leonhard Fuchs and Andreas Vesalius, in Transmitting Knowledge: Words, Images, and Instruments in Early Modern Europe, eds. S. Kusukawa and I. Maclean, (Oxford: Oxford University Press, 2006, 73-96). Inferred uses of classroom technologies such as the carta and tabula suggest a show-and-tell approach was dominant at least for learning letters and basic syllables in our period of interest, but I know of no comprehensive study of spoken language learning among pre-literate children in this period. See R. Black, Humanism and Education in Medieval and Renaissance Italy: Tradition and Innovation in Latin Schools from the Twelfth to the Fifteenth Century, (Cambridge: Cambridge University Press, 2001, 36-37).

6 On the "architecture" of Euclidean pages in manuscript and print, see G. De Young, Mathematical diagrams from manuscript to print: examples from the Arabic Euclidean transmission, Synthese 186(1) (2012): 21-54.

Spontaneous Generations 6:1(2012) 
the several editions published by Hervagius), groupings of diagrams established conceptual relationships between geometric objects while simultaneously stressing the diversity of such objects. The development in dimension from point to line to surface, in particular, can be easily read from most of the texts considered here, a reading aided in several editions by depictions of lines that further dramatize their relationship to points by placing exaggerated dots at their ends in definitional diagrams (and nowhere else).

The dot, in these works, is always already an exaggeration of the point. With the exception of diagrams simultaneously illustrating the second and third definitions of the Elements (defining the line and declaring its ends to be points) or those illustrating the initial definition of a circle (with a point at the center), diagrams for the definition of the point are the only places in these editions where points appear as dots. ${ }^{7}$ Moreover, point diagrams are the only places where it appears obligatory for a dot to be used. There is a simple reason for this: beyond the first definition, points in Euclid's Elements never appear in isolation. Nearly all points in the Elements are conceived of, and depicted as, the ends or intersections of lines and curves. ${ }^{8}$

It is not simply the case that geometers and printers had to draw something and that dots were the only thing available. Modern editions, after all, omit point diagrams entirely. While points' logical and narrative priority in the Elements might lead one to try to depict them without appealing to other geometrical objects, there could be few objections to showing points as the intersections of lines, to showing them as part of a larger figure (for example, as the corner of a cube), or to relying on an appeal to the imagination. Instead, early modern expositors used dots as a specific and constitutive representation of the point with numerous connotations.

Readers, writers, printers, and geometers of the sixteenth century were surrounded by dots. Rapid marks in quill-and-ink joined the impressions of compass tips on a page (some of which remain visible in manuscripts centuries later) and pinholes (long used by printers and artists for a variety of purposes). All of these connotations helped sixteenth-century geometric texts bring the human body into geometry. The act of dotting with an ink pen-stabbing at the page and rapidly withdrawing-or producing a tiny puncture made points gesturally vivid in ways that complemented their visual smallness on the page. Depicting the point with the print analogue of the smallest and fastest mark in manuscript writing helped make its extreme smallness legible while preserving that very legibility-after all, a speck so minuscule as to escape notice cannot be

7 Ratdolt, in addition, puts dots at the ends of other lines in early diagrams to stress correspondences among the lines or their endpoints.

8 This remains the case even when other conceptions and depictions are also in play. For instance, when a point appears as the center of a circle, it is at the same time presented as the end of that circle's radius. 
read as minuscule.

These manual associations had terminological counterparts. While the

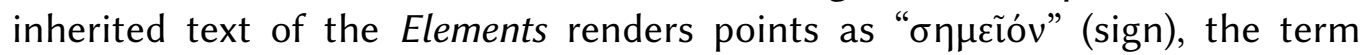
" $\sigma \tau \iota \gamma \mu \eta$ " (prick, puncture) was frequently taken to be interchangeable and was even preferred in some contexts. Indeed, the point appears as punctus (evoking puncture) more often in Latin texts of this period than as the more literal signum (sign). The printed dot conveyed both valences: the visible dot stood as a sign, while its associated gestures indicated puncture. Bariletto $\left(1569,7^{r}\right)$, for instance, describes the image of the point (ponto) as a tiny sign (picollo segno) made by a pointed stylus (stilo pontito). Typographic periods and sharp carving implements for woodcuts were materially available to printers, but, more than that, these tools and their associated manuscript gestures were conceptually available for the production of points.

Graphically precise dots also suggested that the point possessed a location, a property that distinguished points philosophically from other monads such as "a Unit in Number, an Instant in Time, and a Sound in Music" (Leeke and Serle 1661, 2 ). But the primary significance of points' locations was not philosophical but practical. In Euclidean geometry, diagrams are read, interpreted, and referenced almost exclusively through labels attached to point locations. For example, a line containing the points labeled $A$ and $B$ participates in a Euclidean proof as "the line $A B$." Point labels connect descriptive and argumentative prose text with specific forms and locations in diagrams, making possible the dialogue between prose and diagram that Netz (1999) argues is indispensable to Euclidean geometry.

Euclidean geometry was by no means alone in its pragmatic deployment of point loci. In a context where maps, surveys, and navigation were integral parts of many geometers' work, common label-icon denotations for landmarks in geographic maps and the manual practice of compass mensuration (with its association between punctures and locations) made the dot a perspicuous marker of location. It is not hard to speculate that this constellation of label-dot practices surrounding early modern geometry fostered, for geometers, a hybrid practical intuition blending diagrammatic, corporeal, narrative, conceptual, and other features of their work. ${ }^{9}$

There is a particular semiotic lesson offered by the defined term's presence in both the definitional sentence and the diagram's label. This textual repetition offers a visual and semantic link between the words of the definition, on the one hand, and the point's defining image, on the other. Pairing the formulation "that which has no part" and the image of a dot, in this way, suggests a

9 In particular, I would suggest that the narrative and conceptual homologies described by Alexander (1995) between exploration and the geometry of the continuum are part of a much farther-reaching web of associations and practices. See A. Alexander, The imperialist space of Elizabethan mathematics, Studies in the History and Philosophy of Science 26(4) (1995): 559-91. 
conceptual homology that is by no means self-evident. Repeated for each label-image diagram and its associated definition, such a transfer of reference establishes descriptions of objects in statements and proofs as accountably co-equal (albeit not identical) with those objects' manifestations in diagrams. The visual and conceptual rhythm of following labels from text to diagram and back is a constant presence throughout the Euclidean corpus, making pictures into Euclidean pictures and dots and lines into "those which have no part" and "lengths without breadths." Even though the particular label "point" and the particular image of the dot rarely recur beyond the opening of the Elements, the label-dot diagram is thus nevertheless a hallmark of Euclidean legibility.

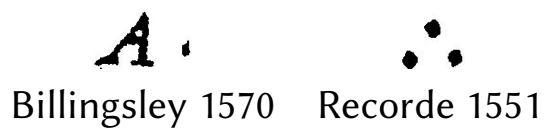

Figure 2. Authors as noted. Variations on label-dot diagrams. ${ }^{10}$

\section{VARIATIONS}

It was not, however, the case that the label-dot diagram was the only depiction to be found in prominent sixteenth-century texts. In mid-century London, two of the most historically-significant Euclidean volumes exemplify possible variations on the label-dot paradigm that would persist into the following century (Figure 2). ${ }^{11}$ Henry Billingsley's 1570 English translation of the Elements uses a "letter-dot" diagram, placing the dot next to an enlarged letter A. The primary definition of the point in Billingsley's text makes no mention of the letter or image, but Billingsley's commentary on the definition refers to "the point $A$ in the margin." Here, there is a third step in the transfer of reference between definition and diagram, passing through a layer of commentary and interpretation, and it is not possible to skip this middle step. Semiotically, then, Billingsley's presentation more closely resembles the proofs and constructions that form the bulk of Euclidean works. In these works, an object is introduced by a generic name (e.g. "square") in the proposition statement, matched to a label in the proof (e.g. "the square $A B C D$ "), and joined via that label to a feature of

${ }^{10}$ Images appear by permission of the Master and Fellows of St John's College, Cambridge (Billingsley) and the Huntington Library (Recorde).

${ }^{11}$ For a survey of English editions of the Elements, see J. Barrow-Green, 'Much necessary for all sortes of men': 450 years of Euclid's Elements in English, BSHM Bulletin: Journal of the British Society for the History of Mathematics 21(1) (2006): 2-25. For an assessment of the diagrams in sixteenth-century English editions, see M. J. Barany, Translating Euclid's diagrams into English, 1551-1571, in Philosophical Aspects of Symbolic Reasoning in Early Modern Mathematics, Studies in Logic, vol. 26., eds. A. Heeffer and M. Van Dyck, (London: College Publications, 2010, 125-63). 
a corresponding diagram (e.g. a familiar shape with four sides and with letter labels at its corners).

Letter-dot diagrams further reconfigure the narrative relation of the definition's words to its diagram. With a label-dot diagram, it is possible to learn (to a significant extent) what is being depicted without any reference to the definitional sentence. Indeed, the obscure and foreign formulations of these sentences in many editions would make them of little use to those not already schooled in geometry, even when they did read them. The letter-dot diagram, by contrast, made reliance on the diagram alone impossible while also requiring the addition of non-definitional text after the definitional sentence in order to tie the definition to the diagram by introducing the point's associated letter.

Where label-dot diagrams could stand largely independent of their associated definitional sentences, letter-dot diagrams were clearly subordinate to the semiotically free-standing prose definitions they accompany. The letter in the letter-dot diagram does not indicate what the dot is without the help of explanatory text. Letter-dot diagrams thus stress the extent to which the diagram is a mere representation of the phenomenon in question. As Netz (e.g. 1998; 1999) describes, by elevating the written exegesis and suppressing the role of the diagram, geometric works efface the extent to which the text is dependent on the diagram for both its coherence and its intelligibility. However effected, the crucial passage of scientific images from "representations" to "mere representations" helps geometers and scientists alike insulate their objects of study from their means of study.

On the one hand, this passage to "mere representations" obscures the symbolic (and often material) violence required to turn natural and conceptual phenomena into workable specimens for analysis. In Lynch's (1985) account of this "rendering" process in a neuroscience laboratory, living rats are thus transformed into pictures of neural growth only through a routinized but gruesome series of researcher actions. While Euclidean geometry tends to be less bloody than Lynch's neuroscience, one ought not presume that its objects come into being any more innocently or transparently. ${ }^{12}$

On the other hand, error-prone "mere representations" are always provisional, never fully accountable for the knowledge-work to which they are enlisted. Thus, a disruptive plot can be dismissed as artifactual (Lynch 1985) or

${ }^{12}$ Alexander (1995) offers a particularly striking example of the often-hidden interplay of mathematical concepts and (in his case, imperial) projects and contexts of more obvious human consequence. To appreciate the gap between geometric phenomena and their means of analysis, however, one need only consider the vast difference between the particular drawn triangles of Euclidean diagrams and the infinities of ideal triangles they supposedly simultaneously represent, on which, cf. Livingston (1986). See A. Alexander, The imperialist space of Elizabethan mathematics, Studies in the History and Philosophy of Science 26(4) (1995): 559-91; and E. Livingston, The Ethnomethodological Foundations of Mathematics, (London: Routledge, 1986). 
a misleading geometric diagram can be cast aside as poorly drawn. In geometry, the relation of "mere representation" between geometric objects and their associated diagrams and non-diagrammatic signs is a fundamental ingredient in the philosophical position of mathematical Platonism. When diagrams are only ever fallible depictions of geometric phenomena, those phenomena's ultimate existence, properties, and relationships are never in question during the messy work of proving. Geometry retains its inevitable truths, its power to compel assent.

Not all modifications to the label-dot scheme were in the direction of abstraction. Robert Recorde's English translation of the Elements includes a lengthy explanation of the point that repeatedly emphasizes sensory intuitions. Recorde's diagram consists of three dots arranged in a triangle, showing points composing a geometric shape but lacking a system of labels. He explicitly invokes pen pricks in his explanation of geometric points and, because there is no auxiliary text in the diagram itself (unlike in those accompanying most of Recorde's other definitions), readers had no choice but to view Recorde's dots in the context of his explanatory prose.

A final mention is due for the handful of geometries lacking point diagrams entirely. One does not see diagrams for points in philosophical disquisitions on the Elements, such as John Dee's long introduction to Billingsley's (1570) translation, even where the point is defined and described in visual terms. Similarly, Ramus (1580) neglects to illustrate his point definition but does include a lengthy discussion of its philosophical ramifications. This suggests that point diagrams were primarily of instrumental use in conveying visual programs of practical and practiced geometry, and could be dispensed with in works that treated geometry on a primarily discursive and philosophical level.

\section{Conclusion}

Leon Battista Alberti's monumental 1435 treatise On Painting begins:

In writing about painting in these short books, we will, to make our discourse clearer, first take from mathematicians those things which seem relevant to the subject.... Mathematicians measure the shape and forms of things in the mind alone and divorced entirely from matter. We, on the other hand, who wish to talk of things that are visible, will express ourselves in cruder terms....

The first thing to know is that a point is a sign which one might say is not divisible into parts. I call a sign anything which exists on a surface so that it is visible to the eye. No one will deny that things which are not visible do not concern the painter, for he strives to represent only the things that are seen. (Translated in Grayson 1972, par. 1-2) 
For Alberti, an avid promoter and consumer of mathematics (Rose 1975), the point is the fundamental unit of vision, the indivisible sign, the first thing to know. Though indivisible, it was nevertheless a highly composite entity. The point was simultaneously visual and gestural, geometric and cartographic, philosophical and technical. Though visible, the act of painting renders points invisible-a finished work can no longer be seen in terms of the putative points of which it must ultimately be composed, in Alberti's view. Painting is a matter of vision, vision a matter of signs: signs can be divided into points, which can be divided no further. The point is thus the beginning of vision, a beginning crudely tethered to the disembodied ideals of mathematics and the constraints of matter alike.

Robert Hooke's 1665 Micrographia likewise begins:

As in Geometry, the most natural way of beginning is from a Mathematical point; so is the same method in Observations and Natural history the most genuine, simple, and instructive.... We will begin these our Inquiries therefore with the Observations of Bodies of the most simple nature first,... we shall begin with a Physical point; of which kind the Point of a Needle is commonly reckon'd for one; and is indeed, for the most part, made so sharp, that the naked eye cannot distinguish any parts of it.

Again, the point is fundamental, indivisible to the naked eye, the most natural way of beginning. Like Alberti, Hooke begins at the intersection of mathematical ideals and crude matter. Yet, under Hooke's microscope, the seemingly indivisible point became a variegated and complex body, full of contours and forms. In a sense, by placing a point under the microscope so as to see it, Hooke causes the point itself to vanish. Hooke's point, like Alberti's, was at once indivisible and highly composite, at once visible and vanishing. ${ }^{13}$

For Alberti and Hooke alike, the point was a beginning. For both, the point was unavoidably something to see. For both, when a representation of the Euclidean point works, it is precisely so as to announce that there is nothing there to see. So runs the problem of visual representation throughout geometry, and indeed throughout science. In the paradoxical manifestation of the "real thing" in its own image, the image-maker must create something to see and then

${ }^{13}$ Schäffner (2005) argues that Hooke thus made the point a problem of exact knowledge, refinement, and precision. While the specific historical influence of Hooke's work was likely more circumscribed than Schäffner might imply, one can nevertheless join Schäffner in appreciating the epistemological problems opened up by the point's paradoxical status under the microscope. See W. Schäffner, The point: The smallest venue of knowledge in the 17th century (1585-1665), in Collection, Laboratory, Theater: Scenes of Knowledge in the 17th Century, eds. Helmar Schramm, Ludger Schwarte, Jan Lazardzig, (Berlin: Walter de Gruyter, 2005, 57-74). 
reduce it to the status of mere representation. Science is awash in visual images, but no credible scientist experiences her work as just image-work. Scientists study objects and phenomena, and the scientificity of scientific representation rests on the double work of making those objects and phenomena appear while making those appearances appear secondary.

How does one begin this double work? The social, technical, logical, and lexical labor of scientific visualization is laden with limits - of data, of perception, of comprehension, of access, of imagination. A scientific image must be both adequate and provisional, deferring to ever-present limits while helping one to look past them. The limiting objects of scientific imagination must, moreover, be adequate and provisional in themselves: they must perform as representations without the conceptual and technical scaffolding with which most scientific knowledge is built. The dot is not born a point; it is made into one. It is so made in spite, and with the help, of its particular size, shape, divisibility, and other features. Its priority in the Elements is achieved, not foregone. Alberti and Hooke, like our sixteenth-century geometers, found in the Euclidean point a limiting object steeped in the paradoxes of representation.

Archimedes asked for just one stable point in order to move the world. But no point can stand on its own. Visual representations, like sixteenth-century depictions of the Euclidean point, are always embedded in a double-edged labor of production and effacement. In science, there are no Archimedean points, just Euclidean ones.

\author{
Michael J. Barany \\ 129 Dickinson Hall \\ Princeton University \\ Princeton, NJ 08544 \\ USA \\ mbarany@princeton.edu
}

\title{
RefERENCES
}

Bariletto, Giovanni. 1569. Euclide Megarense philosopho, solo introduttore delle scientie mathematice. Edition based on 1543 translation by Nicolò Tartaglia. Venice.

Billingsley, Henry. 1570. The Elements of Geometrie of the most auncient Philosopher Euclide of Megara. London: John Daye.

Cavellat, William. 1557. Michael Psellus De arithmetica, musica, geometria: et Proclus De sphæra. Paris.

Cavellat, William. 1558. Euclidis Elementorum libri XV. Paris.

Digges, Leonard. 1571. A Geometrical Practise, named Pantometria. London: Henrie Bynneman. 
Heath, Thomas L. 1956. The Thirteen Books of Euclid's Elements, translated from the text of Heiberg, with introduction and commentary. 2nd ed., revised with additions. Vol. 1: Introduction and Books I, II. New York: Dover.

Hervagius, Johann. 1533. Eukleidou Stoicheion: Bibl. ie' ek ton theonos sunousion; Eis tou autou to proton exegematon Proklou biblios; Adiecta præfatiuncula in qua de disciplinis mathematicis nonnihil. ed. Grynaeus, Simon. Basel.

Hervagius, Johann. 1537. Euclidis Megarensis mathematici clarissimi elementorum geometricorum: Lib. XV. Basel.

Hervagius, Johann. 1558. Euclidis Megarensis mathematici clarissimi Elementorum geometricorum libri XV. Re-edition of 1537 ed., with Bernhard Brand. Basel.

Hooke, Robert. 1665. Micrographia, or, Some physiological descriptions of minute bodies made by magnifying glasses. London: Martyn and Allestry.

Grayson, Cecil. 1972. Leon Battista Alberti: On Painting and On Sculpture. London: Phaidon.

Leeke, John, and George Serle. 1661. Euclid's Elements of Geometry. London: R. \& W. Leybourn.

Lynch, Michael. 1985. Art and Artifact in Laboratory Science: A study of shop work and shop talk in a research laboratory. London: Routledge \& Kegan Paul.

Netz, Reviel. 1998. Greek Mathematical Diagrams: Their Use and Their Meaning. For the Learning of Mathematics 18(3): 33-9.

Netz, Reviel. 1999. The Shaping of Deduction in Greek Mathematics: A Study in Cognitive History. Cambridge: Cambridge University Press.

Paganini, Paganino [Luca Pacioli]. 1523 [1494]. Summa de arithmetica geometria, proportioni, et proportionalita. Re-edition of $1494 \mathrm{ed}$. Toscolano.

Ramus, Petrus. 1580. Arithmeticae libri duo: Geometriae septem et viginti. Basel: Eusebium Episcopium, \& Nicolai fratris hæredes.

Ratdolt, Erhard. 1482. Preclarissimus liber elementorum Euclidis perspicacissimi: in artem Geometrie incipit quam foelicissime. Venice.

Recorde, Robert. 1551. The pathway to knowledg. London: Reynold Wolfe.

Rose, Paul Lawrence. 1975. The Italian Renaissance of Mathematics: Studies on humanists and mathematicians from Petrarch to Galileo. Geneva: Droz.

Stephani, Henrici. 1516. Euclidis Megarensis Geometricorum elementorum libri XV. Paris. 